\title{
Perioperative Complications in Abdominal Sacrocolpopexy, Sacrospinous Ligament Fixation and Prolift Procedures
}

\author{
Fuat Demirci ${ }^{1}$, Oya Demirci ${ }^{2}, Z_{\text {Zehra Nihal Dolgun }}^{3}$, Birgül Karakoç ${ }^{1}$, Elif Demirci ${ }^{2}$, Aslı Somunkıran $^{4}$, \\ Cem İyibozkurt ${ }^{5}$, Erhan Karaalp ${ }^{6}$ \\ ${ }^{1}$ Department of Obstetrics and Gynecology, Kadiköy Şifa Hospital, İstanbul, Turkey \\ ${ }^{2}$ Department of Obstetrics and Gynecology, Zeynep Kamil Women and Children Education and Research Hospital, İstanbul, Turkey \\ ${ }^{3}$ Department of Obstetrics and Gynecology, Yakacık Maternity and Children Hospital, İstanbul, Turkey \\ ${ }^{4}$ Department of Obstetrics and Gynecology, Yeditepe University Faculty of Medicine, İstanbul, Turkey \\ ${ }^{5}$ Department of Obstetrics and Gynecology, İstanbul University Faculty of Medicine, İstanbul, Turkey \\ ${ }^{6}$ Department of Obstetrics and Gynecology, Göztepe Education and Research Hospital, İstanbul, Turkey
}

Background: Pelvic organ prolapse is an important problem for women. To overcome this issue, different operational technics are in use, such as abdominal sacrocolpopexy, sacrospinous fixation, and the total Prolift procedure.

Aims: This study assessed perioperative complications in abdominal sacrocolpopexy, sacrospinous fixation, and the total Prolift procedure.

Study Design: Retrospective comparative study.

Methods: Perioperative complications were defined as any complication occurring during surgery or the first 6 weeks postoperatively. Forty-five patients underwent abdominal procedures, 60 patients underwent sacrospinous fixation, and 43 patients underwent the total Prolift procedure.
Results: In the abdominal group, one bladder injury, four hemorrhages, and three wound dehiscences occurred. In the sacrospinous group, one rectal injury and one postoperative vault infection occurred. In the Prolift group, one bladder injury and one hemorrhage occurred. Minor complications were more frequent in the abdominal group than the others. The operating time and hospital stay of the abdominal group were significantly longer than the others. The Prolift procedure had less operating time and hospital stay than other procedures.

Conclusion: The total Prolift may be a novel alternative for apical prolapse with low perioperative morbidities and complications.

(Balkan Med J 2014;31:158-63).

Key Words: Pelvic organ prolapse, Prolift, sacrocolpopexy, sacrospinous fixation
Prolapse of pelvic organs is an important reason for gynecologic surgery. Although little is known about the pathophysiology, some reasons are speculated for the process, which are mainly relevant to pregnancy, such as macrosomic fetus, prolonged labor, instrumental delivery, and multiparity. Rectocele, enterocele, and cystocele are common co-existing situations with uterovaginal prolapse, showing that this is a complex anatomical disorder. A proper repair can only be done with correct identification and differentiation (1).

The purpose of a reconstructive procedure is the correction and restoration of the prolapse with the most effective longlasting result, which allows sexual functioning and, for young patients, conservation of reproduction (2).

There is a variety of operations for uterovaginal prolapse treatment. The most accepted procedures are vaginal sacrospinous ligament fixation and abdominal sacrocolpopexy/ sacrohysteropexy. Recently, vaginal meshes are being more frequently used in apical prolapse as a kit $(3,4)$. In abdominal sacrocolpopexy, a mesh is used to bridge and hang the cervix or upper vagina to the anterior vertebral ligament in front of the sacral bone. Vaginal sacrospinous ligament fixation was first presented to correct vaginal vault prolapses after hysterectomy (5) but then a wide application area for severe uterovaginal prolapses was found $(6,7)$. The meshes are commercially produced and used as sterile prolapse kits that consist of a fashioned mesh, trocars, or trocars with cannulas.

The aim of our study is to compare the perioperative complications of a prolapse kit (Prolift, Gynecare/Ethicon, Somerville, NJ, USA) with pelvic floor reconstructive procedures for vaginal vault or uterovaginal prolapse, such as transvaginal sacrospinous ligament fixation and abdominal sacrocolpopexy/sacrohysteropexy. 


\section{MATERIAL AND METHODS}

One hundred forty-eight patients` medical records were reviewed for this retrospective study. All patients had vaginal vault or uterovaginal prolapse and were operated on by a single senior surgeon (F.D.). The first part of the study, which consisted of abdominal sacrocolpopexy and sacrospinous fixation, was performed from January 1999 to September 2005 and was published before (8). The second part of the patients underwent Prolift procedure from 2006 to 2011.

After an analysis of the risks, operation time, recovery time, and success rates, the patients ' preferences reflected the selection of the surgical approach. Abdominal and Prolift procedure indications were similar.

Urogynecologic history was taken, and physical examinations, voiding diary, cough test, 1-h pad test, and transvaginal ultrasonography were applied to all patients preoperatively. In selected patients, multichannel urodynamic testing was performed. The POP-Q system (9) was used to stage the pelvic organ prolapse. In our previous study, we had staged 37 patients by the Baden-Walker classification system (10), who are also included in this study. Stage 2 or higher-staged uterine or vaginal vault prolapses were indicated for surgery by POP-Q or Baden-Walker system. In some patients, the cervix was repositioned to evaluate hidden urodynamic stress incontinence (USI), and stress test and urodynamics were performed. The International Continence Society recommendations guided the methods, descriptions, and definitions in this study.

Any complication that occurred during the surgery or postoperatively after 6 weeks was defined as a perioperative complication. Complications were classified as major and minor complications. Potentially life-threatening complications were considered as major complications. Hemoglobin levels were checked preoperatively and postoperatively to evaluate blood loss, and cases requiring blood transfusions were excluded.

\section{Procedure of abdominal sacrocolpopexy/ sacrohysteropexy}

The patients who had abdominal procedures underwent abdominal sacrocolpopexy together with paravaginal repair, Halban/Moskowitz/McCall culdoplasty, or a Burch colposuspension following hysterectomy. Posterior colporrhaphy was also included when necessary. Through a pfannenstiel or infraumbilical midline incision, the peritoneal cavity was entered. Nonabsorbable sutures were used to close the pouch of Douglas in culdoplasty. For sacrocolpopexy and sacrohysteropexy, polypropylene mesh (Prolene, Ethicon, Somerville, USA) was used.

Round ligaments were folded to pull the uterus to its anteverted position in sacrohysteropexy when indicated. The details of the abdominal procedure were explained in our former study (8).

\section{Procedure of sacrospinous ligament fixation}

A right-sided sacrospinous fixation was performed with a twisted needle-holder, applying two non-absorbable sutures together, with anterior and posterior repair performed by delayed-absorbable sutures. Paravaginal repair was performed in six patients instead of anterior colporrhaphy. Five patients had anterior repair, and 6 patients had posterior colporrhaphy with polypropylene mesh. When we first started this study, Burch colposuspension was performed in 11 patients with USI, and a pubovaginal sling was applied to 3 patients with intrinsic sphincter deficiency (ISD) following vaginal hysterectomy and sacrospinous ligament fixation in this sacrospinous group. Afterwards, we switched the operation to a tension-free midurethral polypropylene sling (MPS) application in USI patients following sacrospinous fixation $(9,10)$. To prevent overstabilization of the urethra, MPS was performed before a subsequent anterior colporrhaphy.

\section{The procedure of the total Prolift}

The tension-free vaginal mesh procedure was applied in the fashion Fatton et al. described in their original article (3). Hysterectomy was performed initially if necessary. In order to reduce the risk of mesh exposure and erosions, no $\mathrm{T}$ incisions were used in the patients with cuff prolapse. After the closure of the incisions, a lubricated vaginal pack was placed and kept in the vagina for a day.

Anal sphincteroplasty was performed after the main operations when indicated. Table 1 demonstrates the surgical interventions for each group. Low-molecular-weight heparin was administered to patients who were at risk for pathologic clot formation. All patients received antibiotic prophylaxis. Vaginal estrogen was applied to all postmenopausal women before surgery. In the Prolift group, the urethral catheter was removed on the first postoperative day, and for the rest of the groups, it was removed on the third postoperative day.

The chi-squared test and, for the three-group comparisons, one-way Anova test were used for statistical analysis (SPSS software, version 11.0, Chicago, IL, USA). If significance was detected on the one-way Anova test, Tukey or Tamhane test was used to determine which groups were different, where appropriate. A p value $<0.05$ was considered significant.

\section{RESULTS}

Patients who had abdominal procedures were named Group 1 (G1). This group had 45 patients, with 20 sacrohysteropexy and 25 sacrocolpopexy. The second group was the vaginal sacrospinous fixation group (G2), with 60 patients, and 43 patients had the total Prolift procedure, categorized as the third group (G3). The body mass index and parity of the patients were similar in the three groups. Twenty-seven patients had 
vaginal vault prolapse of 148 patients (six in G2, seven in G1, and 14 in G3). In contrast, the number of previous surgery interventions was significantly higher in G1 and G3 than G2. A significantly higher number of postmenopausal patients were present in G2 than G1 and G3. The patient characteristics and previous pelvic surgery histories for each group are shown in Table 2 .

Concomitant anti-incontinence surgery was performed in 34 patients with USI (ISD in 6) in G1, to 17 patients with USI (ISD in 7) in G3, and to 45 patients with USI (ISD in 7) in G2.

One bladder injury occurred both in the abdominal and Prolift groups and was repaired immediately. Two patients bled during paravaginal repair, two patients bled during sacrocolpopexy, and one patient bled during posterior Prolift. Warm sponge packing was enough for four patients to stop the bleeding, whereas one required homeostasis suture. Blood transfusion was necessary in these patients. Wound dehiscence occurred in three cases over the fascia: one of them was 3 $\mathrm{cm}$ long, the other was $5 \mathrm{~cm}$, and one of them comprised the whole length of the incision.

One rectal injury occurred in the sacrospinous group during pararectal space dissection and was immediately repaired.

Vaginal vault infection was seen in one patient. Seven G1 patients (15.6\%), five $\mathrm{G} 2$ patients $(8.3 \%)$, and two G3 patients (4.6\%) complained of urinary retention lasting more than 5 days. Only one patient who had an MPS needed sling removal after a 30-day catheterization. Ecchymosis of the perineum occurred in $3(7 \%)$ patients in $\mathrm{G} 3$.

We found more frequent minor complications in the abdominal group than the other two groups, whereas there was no statistically significant difference in major complications. The types of the complications are classified in Table 3.

Since the procedures were heterogeneous, operating time, duration of hospital stay, and hemoglobin levels could not be compared among the groups. Uterovaginal prolapse and SUI can be treated by abdominal hysterectomy, sacrocolpopexy, McCall culdoplasty, Burch colposuspension with or without paravaginal repair, and posterior repair (18 patients). The vaginal approach includes vaginal hysterectomy, McCall culdoplasty, sacrospinous fixation, tension-free sling together with anterior repair or paravaginal repair, and posterior repair (29 patients).

There were only 9 patients who had hysterectomy, Prolift procedure, and TVT-O, which can be compared with the former (abdominal and sacrospinous) group. Since hysterectomy is the main operation that is likely to cause blood loss, we compared only these patients in terms of operating time, hemoglobin level, and hospital stay. The comparison of pre- and post-operative hemoglobin levels was not significantly different between the groups. But, in the aspect of hospital stay and operating time, there was a significant prolongation favoring
TABLE 1. Surgical procedures performed in the three groups

\begin{tabular}{lccc}
\hline Procedure & $\begin{array}{c}\text { Abd. group } \\
(\mathrm{n}=45)\end{array}$ & $\begin{array}{c}\text { Sacrospinous group } \\
(\mathrm{n}=60)\end{array}$ & $\begin{array}{c}\text { Prolift } \\
(\mathrm{n}=43)\end{array}$ \\
\hline Sacrocolpopexy & 25 & - & - \\
Sacrohysteropexy & 20 & - & - \\
Sacrospinous fixation & - & 60 & - \\
Total mesh (Prolift) & - & - & 43 \\
Abdominal hysterectomy & 18 & - & - \\
Vaginal hysterectomy & - & 54 & 15 \\
Anterior colporrhaphy & - & 38 & 3 \\
Posterior colporrhaphy & 34 & 55 & 2 \\
Culdoplasty & 45 & 41 & - \\
Burch colposuspension & 5 & 11 & - \\
Paravaginal repair & 24 & - & - \\
Paravaginal repair + Burch & 8 & - & - \\
Pubovaginal sling & - & 3 & - \\
Midurethral polypropylene & 4 & 23 & - \\
sling (MPS) & & & \\
TVT-O & - & - & 17 \\
Vaginal paravaginal repair & - & 4 & - \\
Vaginal paravaginal repair + & - & 2 & - \\
transobturator MPS & & - & - \\
Paravaginal repair + MPS & 2 & - & - \\
Transobturator MPS & 2 & - & - \\
Cervical amputation & 3 & - & - \\
Shortened round ligament & 17 & - & - \\
Ovarian cyst extirpation & 3 & - & - \\
Tubal ligation & 10 & - & - \\
Appendectomy & 9 & - & - \\
Anal sphincteroplasty & 9 & - & - \\
Ripstein rectopexy & 1 & - & - \\
\hline MPS: & - & - & - \\
\hline
\end{tabular}

MPS: midurethral polypropylene sling; TVT-O: transvaginal tape-obturator

TABLE 2. Patient characteristics and previous pelvic surgery in the three groups

\begin{tabular}{|c|c|c|c|c|}
\hline & $\begin{array}{l}\text { Abdominal } \\
\quad(\mathrm{n}=45)\end{array}$ & $\begin{array}{l}\text { Sacrospinous } \\
\quad(\mathrm{n}=60)\end{array}$ & $\begin{array}{l}\text { S } \begin{array}{l}\text { Prolift } \\
(n=43)\end{array}\end{array}$ & $\mathrm{p}$ \\
\hline Age (years) & $43.7 \pm 14.4$ & $58.2 \pm 15.6$ & $44.4 \pm 16.2$ & $<0.001$ \\
\hline Parity (n) & $3.9 \pm 2.7$ & $4.3 \pm 2.5$ & $4.1 \pm 2.4$ & 0.725 \\
\hline Mean BMI, $\mathrm{kg} / \mathrm{m}^{2}$ & $28.6 \pm 5.8$ & $29.1 \pm 5.9$ & $28.7 \pm 6.1$ & 0.899 \\
\hline Postmenopausal patients, (\%) & $14(31.1)$ & $38(63.3)$ & $18(41.9)$ & 0.003 \\
\hline History of pelvic surgery (\%) & $13(28.9)$ & $7(11.7)$ & $17(39.5)$ & 0.004 \\
\hline Vaginal hysterectomy & 5 & 2 & 9 & \\
\hline Abdominal hysterectomy 2 & 4 & 5 & & \\
\hline Needle suspension & 1 & - & - & \\
\hline Marshall-Marchetti-Krantz & 2 & - & - & \\
\hline Anterior colporrhaphy & 6 & 4 & 11 & \\
\hline Posterior colporrhaphy & 8 & 6 & 9 & \\
\hline Sacrospinous fixation & 4 & - & 3 & \\
\hline Modified Gilliam-Dolares & 2 & - & - & \\
\hline
\end{tabular}

BMI: body mass index, $\mathrm{p}<0.05$ : significant

the abdominal group. In the overall analysis, the Prolift group had lower operating time and hospital stay than the abdominal and sacrospinous groups (Table 4). 
TABLE 3. Complications in the three groups

\begin{tabular}{lcccc}
\hline Abdominal & $\begin{array}{c}\text { Sacrospinous } \\
(\mathrm{n}=45)\end{array}$ & $\begin{array}{c}\text { Prolift } \\
(\mathrm{n}=60)\end{array}$ & $(\mathrm{n}=43)$ & $\mathrm{p}$ \\
\hline Major complications & & & & \\
$\quad$ Bladder injury, $\mathrm{n}(\%)$ & $1(2.2)$ & - & $1(2.3)$ & \\
Rectal injury, $\mathrm{n}(\%)$ & - & $1(1.7)$ & - & \\
Hemorrhage, $\mathrm{n}(\%)$ & $4(8.9)$ & - & $1(2.3)$ & \\
Overall major complications, & $5(11.1)$ & $1(1.7)$ & $2(4.6)$ & 0.103 \\
$\mathrm{n}(\%)$ & & & & \\
Minor complications & $7(15.6)$ & $5(8.3)$ & $2(4.6)$ & \\
Urinary retention $(>5$ days), $\mathrm{n}(\%)$ & & & & \\
Urinary infection, $\mathrm{n}(\%)$ & $7(15.6)$ & $6(10.0)$ & $1(2.3)$ & \\
Febrile morbidity, $\mathrm{n}(\%)$ & $4(8.9) 2$ & $2(3.3)$ & $1(2.3)$ & \\
Wound infection, $\mathrm{n}(\%)$ & $5(11.1)$ & $1(1.7)$ & - & \\
Wound dehiscence, $\mathrm{n}(\%)$ & $3(6.7)$ & - & - & \\
Perineal ecchymosis & - & - & $3(7)$ & \\
Overall minor complications, & $26(57.8)$ & $14(23.3)$ & $7(12.2)$ & $<0.001$ \\
$\mathrm{n}(\%)$ & & & & \\
\hline $\mathrm{p}<0.05$ : significant & & & &
\end{tabular}

TABLE 4. Comparison of variables between the three groups

\begin{tabular}{lcccc}
\hline & $\begin{array}{c}\text { Abd. } \\
\text { group } \\
(\mathrm{n}=18)\end{array}$ & $\begin{array}{c}\text { Sacrosp. } \\
\text { froup } \\
(\mathrm{n}=29)\end{array}$ & $\begin{array}{c}\text { Prolift } \\
(\mathrm{n}=9)\end{array}$ & $\mathrm{p}$ \\
Parameter & $191.7 \pm 38.2$ & $40.9 \pm 28.3$ & $118.6 \pm 25.4$ & $<0.001$ \\
\hline Operating time (minutes) & $7.3 \pm 1.8$ & $5.5 \pm 1.9$ & $3.4 \pm 1.4$ & $<0.001$ \\
Hospital stay (days) & $12.3 \pm 0.9$ & $12.1 \pm 1.8$ & $12.2 \pm 1.6$ & 0.909 \\
Preoperative $\mathrm{Hb}(\mathrm{g} / \mathrm{dL})$ & $10.2 \pm 1.3$ & $10.0 \pm 1.7$ & $10.5 \pm 1.5$ & 0.690 \\
Postoperative Hb (g/dL) & 1 & & &
\end{tabular}

\section{DISCUSSION}

Single-compartment defect is rare in symptomatic pelvic prolapse. Therefore, a thorough site-specific evaluation is mandatory to choose the appropriate surgical technique to achieve optimum correction. The widely accepted procedures are vaginal sacrospinous ligament fixation and abdominal sacrocolpopexy, usually combined with different pelvic reconstructive procedures. In recent years, commercially available transvaginal permanent mesh kits with trocars have gained popularity in prolapse surgery with high success rates in early and mid-term follow-up $(11,12)$.

It is hard to analyze the perioperative complications related to uterovaginal surgery. Numerous techniques are described. Moreover, generally, authors emphasize the long-term outcome and efficacy of the procedure rather than complications attributable to the uterovaginal surgery itself.

Nygaard et al. (13) reviewed 65 studies on abdominal sacrocolpopexy (a total of 3827 cases). Our results - hemorrhage ( $8.9 \%$ to $4.4 \%)$, bladder injury ( $2.2 \%$ to $3.1 \%)$, urinary infection $(15.6 \%$ to $10.9 \%)$, and wound infection (11.1\% to $4.6 \%)$ were similar with their review.

In a David-Montefiore et al. (14) review, 16 studies on sacrospinous ligament fixation, each including more than 50 patients (a total of 2292 cases), were evaluated. The rates of urinary infection $(10 \%$ to $14.7 \%)$ and rectal injury $(1.7 \%$ to $0.4 \%$ ) of our study were similar to their review.

In the literature, we found three randomized controlled trials (15-17) that compared abdominal sacrocolpopexy and vaginal sacrospinous ligament fixation operations. In two of three studies, the abdominal approach was superior to the vaginal approach for prolapse repair $(15,16)$. The third study $(17)$ reported that although it was not statistically significant, $17 \%$ of the patients had postoperative recurrent prolapse after vaginal procedures compared to $4 \%$ of those who had abdominal surgery. Benson et al. (15) and Maher et al. (17) reported no significant difference in hospital stay, catheter duration, and blood loss, but the operating time was significantly longer in the abdominal group. Our results are concordant with these studies differing that we also found the duration of hospital stay was also longer in the abdominal group. Maher et al. (17) reported that the vaginal group needed shorter time to return to daily activities.

Benson et al. (15) did not report any significant difference in the two groups' complication rates. In our study, we found that minor complications were more frequent in the abdominal group. In the abdominal and Prolift groups, secondary surgery rates were also significantly more frequent due to indicationrelated reasons, and this may be a risk factor for the morbidity of the patients. One of the patients who bled paravaginally had a history of former anti-incontinence surgery. Contrarily, the mean age and the number of post-menopausal patients were significantly higher in G2 than the other groups. Operation might be challenging for these patients, together with increased morbidity.

In a Cochrane review, abdominal sacrocolpopexy was superior to vaginal sacrospinous fixation, with a decreased rate of recurrent vault prolapse. But, vaginal sacrospinous fixation was rapid to perform and less expensive, with an advantage of early daily activities (18).

In a retrospective multicenter study (3) from the French study group who are the creators of the Prolift, perioperative complications of 684 patients and 300 patients in another study by Kato et al. (19) were evaluated. They found bladder injuries in $0.7 \%$ and $3.7 \%$; rectal injury in $0.15 \%$ and $0.3 \%$; and hemorrhage greater than $200 \mathrm{~mL}$ in $1 \%$ and $0.3 \%$ of patients respectively. Among early postoperative complications were pelvic abscesses in $0.29 \%$ and $0 \%$; pelvic hematomas in $1.9 \%$ and $0.7 \%$; and pelvic cellulitis in $0.15 \%$ and $0 \%$, respectively. In our study, the perioperative complication rates in the Prolift group were comparable to these studies.

There are only three published studies (20-22) comparing vaginal mesh kit complications and recurrence rates with conventional procedures.

In a randomized controlled trial, Withagen et al. (20) compared the efficacy and safety of 93 Prolift procedures with 97 conventional vaginal prolapse repairs in patients with recur- 
rent prolapse. They showed equal improvement in symptoms together with physical functioning at 12 months; however, the tension-free vaginal mesh group had a significantly lower anatomic failure rate.

Sanses et al. (21) compared anatomic outcomes of uterosacral ligament suspension and abdominal sacrocolpopexy with Prolift. In this study, similar to ours, the Prolift group had lower intraoperative blood loss, bladder injury, hemorrhage greater than $500 \mathrm{ml}$, fever, and shorter operating time than abdominal sacrocolpopexy. However, buttock and groin pain was found to be more frequent in the Prolift group. Patients who had the Prolift procedure had similar apical positioning success compared with uterosacral ligament suspension and abdominal sacrocolpopexy, despite lower vaginal apex repositioning 3-6 months after surgery. They stated that the Prolift procedure provides a reasonable alternative prolapse repair approach for patients with higher perioperative risks.

In a meta-analysis of clinical trials and observational studies evaluating apical prolapse repair, Diwadkar et al. (22) reviewed 3425 patients from 24 studies employing vaginal mesh kits and reported a lower rate of reoperation for recurrent POP (1.3\% at 17 months), with an overall peri- and late postoperative complication rate (14.5\%) similar to traditional vaginal procedures (uterosacral ligament suspension, sacrospinous ligament fixation, iliococcygeus fascial suspension, and McCall culdoplasty) (15.3\%) and abdominal sacrocolpopexy (17.1\%). However, due to mesh erosion, the majority of complications associated with mesh kits necessitates surgical intervention under general anesthesia (8.5\%). They speculated that more complications and recurrences might be determined with prolonged follow-up, interpreting a relatively shorter mean pursue period in the mesh kit group. Besides, this may reflect the 'learning curve' of this new procedure. They concluded that further longer-term studies are needed to support these findings definitively.

The weakness of this study is the time periods of operational approaches to pelvic organ prolapse. The first part of the study, which consisted of abdominal sacrocolpopexy and sacrospinous fixation, was performed from January 1999 to September 2005. According to the developments in the mesh industry, the second part of the patients underwent the Prolift procedure from 2006 to 2011. A random operational approach during the same time period might be methodologically more appropriate, but the strength of the study is that the same experienced surgeon had performed all the operations, which standardizes the technique so that the complication rates are dependable.

In conclusion, sacrospinous fixation and Prolift procedures have lower rates of minor perioperative complications and shorter hospital stay and operating time than sacrocolpopexy.
Nevertheless, the Prolift procedure has lower operating time and hospital stay than both vaginal abdominal procedures. It may be a novel alternative for apical prolapse with low perioperative morbidities and complications.

Further randomized controlled studies are necessary to examine the complications, long-term outcomes, and morbidity. The surgical approach should be chosen depending on patient's choice, medical status, age, BMI, previous surgical history, additional pelvic and abdominal procedures, and concurrent pelvic organ prolapse.

Ethics Committee Approval: Ethics committee approval was received for this study.

Informed Consent: N/A..

Peer-review: Externally peer-reviewed.

Author contributions: Concept - F.D., O.D., C.İ., B.K.; Design - F.D., B.K., E.D.; Supervision - F.D., O.D., Z.N.D., B.K., E.D., A.S., C.İ., E.K.; Resource - Z.N.D., B.K., O.D., E.D.; Materials - F.D., A.S., E.K.; Data Collection\&/or Processing - F.D., Z.N.D., E.D.; Analysis\&/or Interpretation - F.D., Z.N.D., O.D., A.S.; Literature Search - C.İ., Z.N.D., E.K.; Writing - F.D., Z.N.D., C.İ., A.S.; Critical Reviews - F.D., O.D., Z.N.D., B.K., E.D., A.S., C.İ., E.K.

Conflict of Interest: No conflict of interest was declared by the authors.

Financial Disclosure: The authors declared that this study has received no financial support.

\section{REFERENCES}

1. Nichols DH. Sacrospinous fixation for massive eversion of the vagina. Am J Obstet Gynecol 1982;142:901-4

2. Shull BL, Capen CV, Riggs MW, Kuehl TJ. Preoperative and postoperative analysis of site-specific pelvic support defects in 81 women treated with sacrospinous ligament suspension and pelvic reconstruction. Am J Obstet Gynecol 1992;166:1764-71. [CrossRef]

3. Fatton B, Amblard J, Debodinance P, Cosson M, Jacqutin B. Transvaginal repair of genital prolapse: preliminary results of a new tension-free vaginal mesh (Prolift technique)--a case series multicentric study. Int Urogynecol J Pelvic Floor Dysfunct 2007;18:743-52. [CrossRef]

4. Caquant F, Collinet P, Debodinance P, Berrocal J, Garbin O, Rosenthal C, et al. Safety of Trans Vaginal Mesh procedure: retrospective study of 684 patients. J Obstet Gynaecol Res 2008;34:449-56. [CrossRef]

5. Randall CL, Nichols DH. Surgical treatment of vaginal inversion. Obstet Gynecol 1971;38:327-32.

6. Cruikshank SH. Sacrospinous fixation should this be performed at the time of vaginal hysterectomy? Am J Obstet Gynecol 1991;164:1072-76. [CrossRef]

7. Porges RF, Smilen SW. Long-term analysis of the surgical management of pelvic support defects. Am J Obstet Gynecol 1991;171:1518-28. [CrossRef]

8. Demirci F, Ozdemir I, Somunkiran A, Topuz S, Iyibozkurt C, Duras Doyran G, et al. Perioperative complications in abdominal sacrocolpopexy and vaginal sacrospinous ligament fixation procedures. Int Urogynecol J Pelvic Floor Dysfunct 2007;18:257-61. [CrossRef] 
9. Brubaker L, Norton P. Current clinical nomenclature for description of pelvic organ prolapse. J Pelvic Med Surg 1996;2:257.

10. Baden WF, Walker TA, Lindsay HJ. The vaginal profile. Tex Med $J$ 1968;64:56-8.

11. Nieminen K, Hiltunen R, Heiskanen E, Takala T, Niemi K, Merikari $\mathrm{M}$, et al. Symptom resolution and sexual function after anterior vaginal wall repair with or without polypropylene mesh. Int Urogynecol $\mathbf{J}$ 2008;19:1611-6. [CrossRef]

12. Jacquetin B, Fatton B, Rosenthal C, Clavé H, Debodinance P, Hinoul P, et al. Total transvaginal mesh (TVM) technique for treatment of pelvic organ prolapse: a 3-year prospective follow-up study. Int Urogynecol J 2010;21:1455-62. [CrossRef]

13. Nygaard IE, McCreery R, Brubaker L, Connolly A, Cundiff G, Weber AM, et al. Abdominal sacrocolpopexy: a comprehensive review. Obstet Gynecol 2004;104:805-23. [CrossRef]

14. David-Montefiore E, Garbin O, Hummel M, Nisand I. Sacrospinous ligament fixation peri-operative complications in 195 cases: visual approach versus digital approach of the sacro- spinous ligament. Eur $J$ Obstet Gynecol Reprod Biol 2004;116:71-8. [CrossRef]

15. Benson JT, Lucente V, Mc Clellan E. Vaginal versus abdominal reconstructive surgery for the treatment of pelvic support defects: a prospective randomized study with long-term outcome evaluation. Am J Obstet Gynecol 1996;175:1418-22. [CrossRef]

16. Lo TS, Wang AC. Abdominal colposacropexy and sacrospinous ligament suspension for severe uterovaginal prolapse: a comparison. $J G y-$ necol Surg 1998;14:59-64. [CrossRef]

17. Maher CF, Qatawneh AM, Dwyer PL, Carey MP, Cornish A, Schuleter PJ. Abdominal sacrocolpopexy or vaginal sacrospinous colpopexy for vaginal vault prolapse: a prospective randomized study. Am J Obstet Gynecol 2004;190:20-6. [CrossRef]

18. Maher C, Feiner B, Baessler K, Adams EJ, Hagen S, Glazener CM. Surgical management of pelvic organ prolapse in women. Cochrane Database Syst Rev 2010; 14: CD004014. doi: 10.1002/14651858. CD004014. pub4 [CrossRef]

19. Kato K, Suzuki S, Yamamoto S, Furuhashi K, Suzuki K, Murase T, et al. Clinical pathway for tension-free vaginal mesh procedure: evaluation in 300 patients with pelvic organ prolapsed. Int J Urol 2009;16:314-7. [CrossRef]

20. Withagen MI, Milani AL, den Boon J, Vervest HA, Vierhout ME. Trocar-guided mesh compared with conventional vaginal repair in recurrent prolapse: a randomized controlled trial. Obstet Gynecol 2011;117:242-50 [CrossRef]

21. Sanses TV, Shahryarinejad A, Molden S, Hoskey KA, Abbasy S, Patterson D, Saks EK, et al. Anatomic outcomes of vaginal mesh procedure (Prolift) compared with uterosacral ligament suspension and abdominal sacrocolpopexy for pelvic organ prolapse: a Fellow's Pelvic Research Network study. Am J Obstet Gynecol 2009;5:519.e1-8.

22. Diwadkar GB, Barber MD, Feiner B, Maher C, Jelovsek JE. Complication and reoperation rates after apical vaginal prolapse surgical repair: a systematic review. Obstet Gynecol 2009;113:367-73. [CrossRef] 